\title{
The Unstimulated Salivary Flow Rate in a Jordanian Healthy Adult Population
}

\author{
Faleh A. Sawair ${ }^{\mathrm{a}, \mathrm{c}}$, Soukaina Ryalat ${ }^{\mathrm{a}}$, Mohammad Shayyab ${ }^{\mathrm{a}}$, Takashi Saku ${ }^{\mathrm{b}}$
}

\begin{abstract}
Background: Early diagnosis of xerostomia is very important for oral health. The purpose of this study was to determine the unstimulated whole salivary flow rates (UWSFR) in a Jordanian Arab population aged 15 years and older. The effect of age, gender, height, weight, body mass index (BMI), smoking, alcohol consumption, and dental conditions, on UWSFR was also investigated.
\end{abstract}

Methods: The study was conducted on 244 subjects, 110 males and 134 females, with an average age of $33 \pm 15.5$ years. They were healthy, unmedicated, and with no history of dry mouth. Unstimulated whole saliva was collected during five minutes, and UWSFRs $(\mathrm{ml} / \mathrm{min})$ were determined. Data were analyzed by univariate analysis and multivariate regression analysis.

Results: The mean UWSFR was $0.46 \pm 0.25 \mathrm{ml} / \mathrm{min}$ (range: 0.10 $1.6 \mathrm{ml} / \mathrm{min})$. Eighteen patients $(7.4 \%)$ had UWSFR $<0.20 \mathrm{ml} /$ min. In univariate analysis, UWSFR was significantly affected by age, BMI, number of missing and restored teeth, and DMFT score. Regression analysis revealed that only age and number of missing teeth were of significance in explaining the variability of the UWSFR.

Conclusions: We established basic standard values of UWSFR to be used in the evaluation of Jordanian patients with complaints of xerostomia and to be compared to data reported in other studies. UWSFR $0.1 \mathrm{ml} / \mathrm{min}$ could be considered the cut-off value that distinguishes normal from abnormal salivary function in this healthy unmedicated population.

\footnotetext{
Manuscript accepted for publication May 27, 2009

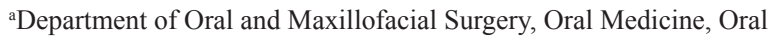
Pathology and Periodontology, Faculty of Dentistry, University of Jordan. Amman, Jordan.

${ }^{b}$ Division of Oral Pathology, Department of Tissue Regeneration and Reconstruction, Niigata University Graduate School of Medical and Dental Sciences, Niigata, Japan.

${ }^{\mathrm{c} C}$ Corresponding author: Faculty of Dentistry, University of Jordan, Amman-Jordan. Email: sawair@ju.edu.jo
}

doi:10.4021/jocmr2009.10.1267
Keywords: Whole saliva flow rate; Unstimulated; Jordan

\section{Introduction}

The knowledge of normal salivary flow rate (SFR) is extremely important when treating dental patients. Early diagnosis and treatment of hyposalivation will preserve the health of oral structures and lower the incidence of dental caries, fungal infections, and other oral diseases that could result from insufficient SFR $[1,2]$. Xerostomia can be caused by many reasons including medications, head and neck irradiation, anxiety or depression, Sjogren's syndrome, and systemic diseases such as diabetes mellitus and some autoimmune disorders [1]. Although many methods can be used to evaluate salivary function, collecting unstimulated whole saliva is the method most frequently used. This method can be easily conducted without any special equipment or physical stress on subjects [3].

Several studies were conducted to establish a critical limit of UWSFR to separate subjects with salivary gland hypofunction from those with normal gland function [4-8]. No consensus has been reached; the critical limit was $0.1 \mathrm{ml} /$ min by some researchers $[4,5]$, while by others it was 0.15 $\mathrm{ml} / \mathrm{min}$ [6], $0.16 \mathrm{ml} / \mathrm{min}$ [7], or $0.20 \mathrm{ml} / \mathrm{min}$ [8]. The normal ranges for SFR were also variable (Table 1).

However, it is difficult to compare SFR reported by different studies due to variations in study design. Differences exist in terms of sample size, patient's gender, age, height, weight, BMI, salivary gland size, diet, or bite force $[3,6,9,10,12-14]$ and in many of these studies these factors were not studied in multivariate analysis. Many investigators studied the prevalence of hyposalivation and, therefore, their samples included patients with systemic diseases or those taking xerostomic medications or had complaints of oral dryness $[9,10]$. Furthermore, the results of different studies are difficult to compare due to variations in circumstances under which UWSFR was collected. Saliva is secreted in a circadian and circannual rhythm and the time of measurement of UWSFR strongly influences SFR [15]. Factors such as thinking of food, visual stimulation, body posture, degree 
Table 1. Results of previous studies that measured unstimulated whole salivary flow rate (UWSFR)

\begin{tabular}{|c|c|c|c|c|c|}
\hline Authors & Country & $\begin{array}{l}\text { Number of subjects, } \\
\text { (male/female) }\end{array}$ & Age & $\begin{array}{l}\text { UWSFR ml/min } \\
(\text { mean } \pm \text { SD) }\end{array}$ & Notes \\
\hline Yamamoto et al [3] & Japan & $200,(100 / 100)$ & $22-29$ & $0.053 \pm 0.032$ & $\mathrm{H} / \mathrm{UM}$ \\
\hline $\begin{array}{l}\text { Fenoll-Palomares et } \\
\text { al [6] }\end{array}$ & Spain & $159,(52 / 107)$ & $44 \pm 14$ & Range: $0.10-2.0$, median: 0.48 & $\mathrm{H} / \mathrm{UM}$ \\
\hline Flink et al [9] & Sweden & $1420,(663 / 757)$ & $\geq 20$ & $0.29 \pm 0.24$ & Dry/M \\
\hline Bergdahl [10] & Sweden & $1427,(669 / 758)$ & $20-69$ & $\begin{array}{l}0.33 \pm 0.26 \text { (male) } \\
0.26 \pm 0.21 \text { (female) }\end{array}$ & Dry/M \\
\hline Percival et al [11] & UK & $116,(55 / 61)$ & $\geq 20$ & $\begin{array}{l}0.50 \pm 0.04(\text { male })(\text { mean } \pm S E M) \\
0.33 \pm 0.03(\text { female })(\text { mean } \pm \mathrm{SEM})\end{array}$ & $\mathrm{H} / \mathrm{UM}$ \\
\hline Shern et al [12] & USA & $51,(25 / 26)$ & $54 \pm 19$ & Mean: 0.61 & $\mathrm{H} / \mathrm{UM}$ \\
\hline Marton et al [13] & Hungary & $24,(?)$ & $67 \pm 8$ & $0.39 \pm 0.25$ & $\mathrm{CD}$ \\
\hline
\end{tabular}

SD: standard deviation, H/UM: healthy and unmedicated. CD: complete dentures, Dry/M: patients who had oral dryness or other oral complaints or those who take xerostomic drugs were not excluded, SEM: standard error of mean.

of room lighting, nausea, earlier chewing of gum or physical exercise, could influence SFR and are difficult to standardise in different studies [16].

Bjornstad and Crossner [17] have conducted a comparative study and found significant variations in SFRs between subjects from Greenland and Sweden and highlighted the importance of being cautious when exchanging reference data between people from different cultures or ethnic groups. This variation may affect the critical limit of SFR that separates patients with xerostomia from those with normal flow rates. Significant differences in UWSFR were also reported when children from USA and Brazil were compared [18]. To the best of our knowledge, no studies were conducted in Jordan or in the Arab world to establish normal ranges of SFR.

The aim of this study was to evaluate the normal UWSFR and identify independent factors affecting this flow among healthy adult Jordanian population. The results may help in establishing the critical limit of UWSFR that separates Jordanian subjects with normal salivary gland function from those with gland hypofunction and for comparison with data reported in other studies.

\section{Materials and Methods}

The salivary glands are fully developed in terms of flow rate at the age of 15 years [19]. Therefore, this study was conducted on 244 volunteers ranging in age from 15 to 76 years chosen in an at-random way from subjects who attended the Department of Dentistry, University of Jordan
Hospital, Amman, Jordan, for dental treatment in the period between January and April 2009. The purpose of the study was explained and all subjects had given their informed consent for participation. Patients were medically healthy without taking any medications known to affect salivary flow. They were excluded if they had acute or chronic diseases of the oral mucosa or salivary glands including xerostomia or oral burning sensation, if they had moderate or severe periodontal disease, or if they had partial or complete dentures or orthodontic appliances. Information about age, gender, height, weight, BMI, smoking history, and alcohol consumption were collected. BMI was recorded as: underweight $<18.5 \mathrm{~kg} / \mathrm{m}^{2}$; normal weight $18.5-24.9 \mathrm{~kg} / \mathrm{m}^{2}$; over weight $25-29.9 \mathrm{~kg} / \mathrm{m}^{2}$; and obese $\geq 30 \mathrm{~kg} / \mathrm{m}^{2}$.

Patients were then clinically examined to rule out acute or chronic diseases of oral mucosa or salivary glands. DMFT (decayed, missing, and filled teeth) index of all permanent teeth excluding third molars was determined for each subject under artificial light, using a dental explorer, flat-surface mouth mirror, gauze, and compressed air according to the WHO diagnostic criteria [20]. Under standard temperature and humidity conditions, UWSFRs were determined in the morning between 10 a.m. and noon. Amounts of liquids ingested by subjects were not studied but all subjects refrained from smoking or intake of any food or beverage at least one hour before saliva collection [21]. Subjects were instructed to relax for 5 minutes and to swallow all saliva present in their mouths before starting saliva collection. While seated and leaning forward, they were told to spit all the saliva they produce into a graduated test tube through a glass funnel. 
Table 2. Patients characteristics and its relation to unstimulated whole salivary flow rate (UWSFR)

\begin{tabular}{|c|c|c|c|c|c|}
\hline \multirow{2}{*}{ Variables } & & \multirow{2}{*}{ Number (\%) } & \multicolumn{3}{|c|}{ UWSFR (ml/min) } \\
\hline & & & Mean (SD) & Range & P value* \\
\hline \multirow[t]{2}{*}{ Gender } & Male & $110(45.1)$ & $0.44(0.24)$ & $0.10-1.30$ & 0.16 \\
\hline & Female & $134(54.9)$ & $0.48(0.26)$ & $0.12-1.60$ & \\
\hline \multirow[t]{6}{*}{ Age (year) } & $15-19$ & $32(13.1)$ & $0.71(0.32)$ & $0.20-1.30$ & $<0.001$ \\
\hline & $20-29$ & $106(43.4)$ & $0.47(0.25)$ & $0.12-1.60$ & \\
\hline & $30-39$ & $32(13.1)$ & $0.41(0.17)$ & $0.20-0.82$ & \\
\hline & $40-49$ & $28(11.5)$ & $0.41(0.17)$ & $0.10-0.72$ & \\
\hline & $50-59$ & $29(11.9)$ & $0.37(0.15)$ & $0.18-0.78$ & \\
\hline & $\geq 60$ & $17(7.0)$ & $0.30(0.15)$ & $0.12-0.50$ & \\
\hline \multirow[t]{2}{*}{ Smoking } & Non-smoker & $175(71.7)$ & $0.47(0.25)$ & $0.12-1.60$ & 0.45 \\
\hline & Smoker & $69(28.3)$ & $0.44(0.25)$ & $0.10-1.24$ & \\
\hline \multirow[t]{2}{*}{ Alcohol } & No & $238(97.5)$ & $0.47(0.25)$ & $1.00-1.60$ & 0.20 \\
\hline & Yes & $6(2.5)$ & $0.33(0.12)$ & $0.20-0.50$ & \\
\hline \multirow[t]{5}{*}{ Height (m) } & $<1.6$ & $20(8.2)$ & $0.49(0.33)$ & $0.20-1.60$ & 0.25 \\
\hline & $1.6-1.69$ & $95(38.9)$ & $0.47(0.24)$ & $0.12-1.24$ & \\
\hline & $1.7-1.79$ & 73 (29.9) & $0.44(0.22)$ & $0.12-1.10$ & \\
\hline & $\geq 1.8$ & $31(12.7)$ & $0.54(0.30)$ & $0.10-1.30$ & \\
\hline & Missing data & $25(10.2)$ & & & \\
\hline \multirow[t]{4}{*}{ Weight (kg) } & $<60$ & $74(30.3)$ & $0.51(0.27)$ & $0.12-1.60$ & 0.10 \\
\hline & $60-79$ & $87(35.7)$ & $0.47(0.26)$ & $0.12-1.30$ & \\
\hline & $\geq 80$ & $59(24.2)$ & $0.42(0.21)$ & $0.10-1.00$ & \\
\hline & Missing data & $24(9.8)$ & & & \\
\hline \multirow[t]{5}{*}{ BMIף } & Underweight & $12(4.9)$ & $0.59(0.39)$ & $0.20-1.60$ & 0.007 \\
\hline & Normal weight & $134(54.9)$ & $0.50(0.28)$ & $0.12-1.30$ & \\
\hline & Overweight & $53(21.7)$ & $0.41(0.22)$ & $0.10-1.24$ & \\
\hline & Obese & $20(8.2)$ & $0.35(0.14)$ & $0.12-0.60$ & \\
\hline & Missing data & $25(10.2)$ & & & \\
\hline
\end{tabular}

*P value of Student's t test or ANOVA, BMIๆ: underweight $<18.5 \mathrm{~kg} / \mathrm{m}^{2}$, normal weight $18.5-24.9 \mathrm{~kg} / \mathrm{m}^{2}$, overweight $25-29.9 \mathrm{~kg} / \mathrm{m}^{2}$, obese $\geq 30 \mathrm{~kg} / \mathrm{m}^{2}$.

The unstimulated whole saliva collected for 5 minutes was then measured by volume and expressed as millilitres per minute $(\mathrm{ml} / \mathrm{min})$ [21]. Clinical examinations and SFR measurements were made by one examiner (S.R.).

Statistical analysis was performed using SPSS for Windows release 16.0 (SPSS Inc., Chicago, IL, USA). Descriptive statistics were generated. Student's t-test, One-WayANOVA test, and Pearson's Correlations test (r) were used to examine differences between groups. When One-WayANOVA test was conducted, post hoc multiple comparisons were used to see which pairs of means were statistically significant. Multiple Stepwise Linear Regression analysis was applied for the determination of the best predictors of UWSFR among gender, age, height, weight, BMI, smoking and alcohol consumption, and dental variables. Coefficients of regression and 95\% Confidence Intervals (CI) were calcu- 
lated for each significant independent variable. Results were considered significant if P-values were less than 0.05 .

\section{Results}

\section{Subjects}

Characteristics of the subjects recruited in the present study are shown in table 2 . They were 244 in number, 110 males and 134 females, and their age ranged from 15 to 76 years with an average of 33 years ( \pm 15.5 years). Mean age for males was $36.0 \pm 15.9$ years and that for females was $30.5 \pm 14.9$ years $(\mathrm{P}=0.006)$. Smokers were significantly older than non-smokers $(36.8 \pm 16.5$ vs. $31.5 \pm 15.0$ years, $\mathrm{P}$ $=0.02)$. There was statistically significant positive correlation between age and BMI $(\mathrm{r}=0.53, \mathrm{P}<0.001)$. Mean BMI for males was significantly higher than that for females (24.9 \pm 3.9 vs. $22.6 \pm 4.3, \mathrm{P}<0.001)$. A significant positive correlation was found between age and number of decayed teeth ( $\mathrm{r}=0.38, \mathrm{P}<0.001)$, number of missing teeth $(\mathrm{r}=0.50, \mathrm{P}<$ $0.001)$, number of restored teeth $(\mathrm{r}=0.34, \mathrm{P}<0.001)$, and DMFT score $(r=0.63, P<0.001)$. Males and females did not differ significantly in the mean number of decayed, missing, and restored teeth, or in DMFT score.

\section{Salivary flow rate}

The mean UWSFR was $0.46 \pm 0.25 \mathrm{ml} / \mathrm{min}$ and the median flow rate was $0.42 \mathrm{ml} / \mathrm{min}$ (range $0.10-1.6 \mathrm{ml} / \mathrm{min}$, percentile $5=0.16 \mathrm{ml} / \mathrm{min}$ and percentile $95=0.92 \mathrm{ml} / \mathrm{min}$ ). None of the patients had UWSFR less than $0.1 \mathrm{ml} / \mathrm{min}$. However, 18 patients $(7.4 \%$ ) had UWSFR $<0.20 \mathrm{ml} / \mathrm{min}$.

\section{Relationship between UWSFR and patients variables}

The relationships between UWSFR and patients variables are shown in table 2. Mean UWSFR in males, smokers or alcohol drinkers did not differ significantly from that in females, non-smokers or non-alcohol drinkers. No significant correlation was found between UWSFR and patient's height $(\mathrm{r}=0.06, \mathrm{P}=0.36)$ or weight $(\mathrm{r}=-0.12, \mathrm{P}=0.08)$, the differences in UWSFR were not significant when the subjects were separated into four groups according to their height or into three groups according to their weights.

UWSFRs decreased significantly as age increased $(\mathrm{r}=$ -0.36, $\mathrm{P}<0.001)$. Post hoc multiple comparisons revealed that UWSFR in subjects younger than 20 years old was significantly higher than the flow rate detected in the other age groups, UWSFR in subjects 20-29 years old was significantly higher than those $\geq 60$ years old, but the differences in

Table 3. Patients dental conditions and its relation to unstimulated whole salivary flow rate (UWSFR)

\begin{tabular}{|c|c|c|c|c|c|}
\hline \multirow{2}{*}{ Variables } & & \multirow{2}{*}{ Number (\%) } & \multicolumn{3}{|c|}{ UWSFR (ml/min) } \\
\hline & & & Mean (SD) & Range & Pvalue* \\
\hline \multirow[t]{3}{*}{ Decayed teeth } & None & $66(27.0)$ & $0.50(0.31)$ & $0.12-1.30$ & 0.28 \\
\hline & $1-5$ & $136(55.7)$ & $0.46(0.24)$ & $0.10-1.60$ & \\
\hline & $>5$ & $42(17.2)$ & $0.42(0.15)$ & $0.16-0.70$ & \\
\hline \multirow[t]{3}{*}{ Missing teeth } & None & $137(56.1)$ & $0.54(0.28)$ & $0.12-1.60$ & $<0.001$ \\
\hline & $1-5$ & $94(38.5)$ & $0.38(0.15)$ & $0.10-0.78$ & \\
\hline & $>5$ & $13(5.3)$ & $0.24(0.08)$ & $0.12-0.40$ & \\
\hline \multirow[t]{3}{*}{ Restored teeth } & None & $56(23.0)$ & $0.57(0.27)$ & $0.12-1.30$ & 0.002 \\
\hline & $1-5$ & $143(58.6)$ & $0.43(0.23)$ & $0.10-1.24$ & \\
\hline & $>5$ & $45(18.4)$ & $0.42(0.25)$ & $0.12-1.60$ & \\
\hline \multirow[t]{5}{*}{ DMFT } & 0 & $18(7.4)$ & $0.64(0.33)$ & $0.16-1.30$ & $<0.001$ \\
\hline & $1-5$ & $83(34.0)$ & $0.50(0.27)$ & $0.12-1.24$ & \\
\hline & $6-10$ & 73 (29.9) & $0.46(0.25)$ & $0.10-1.60$ & \\
\hline & $11-15$ & $48(19.7)$ & $0.41(0.14)$ & $0.16-0.70$ & \\
\hline & $>15$ & $22(9.0)$ & $0.29(0.13)$ & $0.12-0.70$ & \\
\hline
\end{tabular}

${ }^{*} \mathrm{P}$ value of ANOVA 
Table 4. Significant independent predictors of unstimulated whole salivary flow rate (UWSFR) in multivariate analysis

\begin{tabular}{lllll}
\hline & B & $\boldsymbol{\beta}$ & $\mathbf{9 5 \%}$ CI (B) & $\begin{array}{l}\boldsymbol{P} \\
\text { value }\end{array}$ \\
\hline Constant & 0.615 & - & 0.544 to 0.687 & $<0.001$ \\
Age & -0.004 & -0.250 & -0.006 to -0.002 & $<0.001$ \\
Missing teeth & -0.015 & -0.162 & -0.027 to -0.002 & 0.021 \\
\hline
\end{tabular}

B: un-standardized regression coefficient. $\beta$ : standardized regression coefficient, $\mathrm{Cl}$ : confidence interval. $\mathrm{R}=36 \%$, adjusted $\mathrm{R}^{2}=$ $12 \%$

flow rates between patients in the age groups 30-39, 40-49, 50-59 were not statistically significant. Another significant negative correlation was also found between UWSFR and BMI $(r=-0.18, P=0.007)$. The major and statistically significant difference revealed by post hoc comparisons was between obese subjects and those who were underweight or of normal weight; differences between the other groups were not statistically significant (Table 2).

Patients' dental conditions are shown in table 3. Significant negative correlations were found between UWSFR and the number of missing teeth $(\mathrm{r}=-0.29, \mathrm{P}<0.001)$, number of restored teeth $(\mathrm{r}=-0.18, \mathrm{P}=0.005)$, and DMFT score $(\mathrm{r}=$ $-0.31, \mathrm{P}<0.001)$.

The differences in flow rates between patients' subgroups according to number of missing teeth, filled teeth, or DMFT score were statistically significant (Table 3). All post hoc comparisons between the three groups of subjects according to number of missing teeth (none, $1-5$, and $>5$ teeth missing) were statistically significant. In terms of restored teeth, patients who had no restored teeth had significantly higher flow rate compared with patients who had 1-5 or more filled teeth, differences between patients who had 1-5 and those who had $>5$ filled teeth were not statistically significant. Post hoc comparisons revealed that UWSFR in subjects who had zero DMFT score was significantly higher than that detected in all groups having DMFT score $>5$. UWSFR in subjects who had $>15$ DMFT score was significantly lower than that detected in all groups having DMFT score $<10$. The correlation of UWSFR with number of decayed teeth did not reach statistical significance $(r=-0.12, \mathrm{P}=0.06)$ and differences in flow rates between the three groups of patients according to number of decayed teeth were not statistically significant.

\section{Multivariate analysis}

Multivariate regression analysis revealed two factors as significant independent predictors of UWSFR (Table 4).
When the effects of other factors were controlled, age and number of missing teeth were found to be the most important factors. For every one year increase in age, resting salivary flow rate would decrease 0.002 to $0.006 \mathrm{ml} / \mathrm{min}$ (average $0.004 \mathrm{ml} / \mathrm{min}, \mathrm{P}<0.001)$. In addition, for every one tooth loss, UWSFR would decrease by 0.002 to $0.027 \mathrm{ml} / \mathrm{min}$ (average $0.015 \mathrm{ml} / \mathrm{min}, \mathrm{P}=0.021$ ).

\section{Discussion}

As mentioned before, there is no general agreement about UWSFR that distinguishes normal patients from those with hyposalivation; the value has ranged between 0.1 and $0.2 \mathrm{ml} / \mathrm{min}$ [4-8]. As a result, many investigators classify their patients into three groups: those with very low SFR (UWSFR $<0.1 \mathrm{ml} / \mathrm{min}$ ); those with low SFR (UWSFR = $0.1-0.19 \mathrm{ml} / \mathrm{min}$ ); and those who have normal SFR (UWSFR $\geq 0.2 \mathrm{ml} / \mathrm{min}$ ) [9]. In this study, considerable variation was observed in UWSFR, 0.1 to $1.6 \mathrm{ml} / \mathrm{min}$ and $90 \%$ of the subjects (those between percentile 5 and 95) had UWSFR that ranged between 0.16 and $0.92 \mathrm{ml} / \mathrm{min}$. No patients had flow rate below $0.1 \mathrm{ml} / \mathrm{min}$ but 18 patients $(7.4 \%)$ had UWSFR between 0.10 and $0.19 \mathrm{ml} / \mathrm{min}$. Although the latter $7.4 \%$ of the patients are considered having low UWSFR according to the previous classification, none of them had signs or symptoms of oral dryness. This indicates high inter-individual variability in the amount of saliva necessary for oral health. Since $0.1 \mathrm{ml} / \mathrm{min}$ UWSFR was the lowest rate of secretion found in this study and because patients who had complaints of oral dryness were excluded, $0.1 \mathrm{ml} / \mathrm{min}$ UWSFR could be considered the cut-off value that distinguishes normal from abnormal salivary function in this healthy unmedicated population.

Considerable variation in mean UWSFR in adult patients is evident when studies carried out in different countries are compared. The mean UWSFR ranged between $0.053 \mathrm{ml} / \mathrm{min}$ [3] to $0.61 \mathrm{ml} / \mathrm{min}$ [12]. Although comparisons are difficult to be made between studies due to considerable variations in study designs, the mean UWSFR for Jordanian subjects measured in this study is nearly comparable to that reported by studies conducted in Spain [6] and UK [11], higher than that reported in a Japanese study [3], but lower than that reported in a study conducted in USA [12] on healthy unmedicated adult patients.

For accurate evaluation of main UWSFR, it is important to control for the significant independent factors that influence SFR using multivariate statistical analysis. In this study, only age and number of missing teeth were independent predictors of UWSFR. Therefore, these two factors should be controlled when comparisons are made between Jordanian patients. In adult healthy unmedicated Jordanians, UWSFR decreased significantly as age and number of missing teeth increased. However, in the multivariate regression 
model, these two independent variables explained only $12 \%$ $\left(\mathrm{R}^{2}\right)$ of the differences in SFRs between individuals of the study sample. The low prediction rate highlights the need for additional studies to explain the variations in SFRs in this population.

Unstimulated salivary flow is produced primarily by the submandibular salivary glands $(65-70 \%)$, with the parotid and sublingual glands providing $20 \%$ and $7 \%$ to the flow, respectively [16]. Research has shown diminution of both stimulated and unstimulated submandibular SFR with increasing age [22] but the reasons behind this finding were not clear. In this study, none of the patients suffered from systemic or salivary gland diseases and none were taking medication that could compromise SFR. Therefore, our finding that UWSFR decreases significantly with increasing age, a finding in agreement with several previous reports $[6,7$, $11,23]$, is difficult to explain. The reduction could result from structural changes affecting the submandibular salivary glands. In fact, age-related gradual loss of secretory tissue of the submandibular glands and replacement with fat and connective tissue has been reported [24]. In contrast to submandibular glands, in healthy individuals parotid gland function is not affected by the aging process as was shown by some investigators $[11,25,26]$ and, since the parotid glands supply about $60 \%$ of the stimulated whole saliva [16], reports have shown no decrease in stimulated whole salivary flow rates with increasing age $[27,28]$. In fact, some reports have shown an unexplainable increase in stimulated salivary gland secretion with increasing age $[7,12]$.

The effect of the number of teeth on UWSFR has not been fully investigated. The results in this study showed that UWSFR decreased significantly as number of missing teeth increased. Flink et al [9] have reported that patients who had fewer than 20 teeth had significantly more prevalent very low stimulated $(<0.70 \mathrm{ml} / \mathrm{min})$ and unstimulated $(<0.10 \mathrm{ml} /$ min) SFRs. The authors explained this relationship by the possible increase in caries activity and subsequent loss of teeth secondary to reduced salivary flow. In this study no significant association was found between the number of decayed teeth and UWSFR. Since the relationship between caries and SFR was only confirmed in patients with very low (< $0.10 \mathrm{ml} / \mathrm{min}$ ) SFR [29], this finding was expected since we did not recruit subjects who had suspected hyposalivation. An alternative explanation to the relation between missing teeth and UWSFR was shown by Yeh et al [23] who have reported a significant correlation between salivary flow rate and maximum bite force independent of age and gender, a decrease in bite force strength was associated with a decrease in UWSFR. According to the authors, the loss of teeth was considered an apparent reason responsible for the decrease in bite force and subsequent decrease in salivary flow rate. Therefore, it is unclear whether hyposalivation leads to loss of teeth or loss of teeth decreases the SFR, and further studies to explore this topic are needed.
Conflicting results were reported on UWSFR in relation to gender. Our data indicated no significant difference between males and females in terms of resting salivary flow. Similar findings were reported by Shern et al [12]. In contrast, some investigators have found that males had higher secretion rates of unstimulated saliva compared with females $[9,11]$. It is possible that the effect of gender is not genuine and secondary to other factors highlighting the importance of multivariate analysis. Some investigators have attributed this difference to greater glandular mass in males [30], differences in hormonal patterns [31], or differences in BMI [3]. Therefore, when the effects of body profiles and glandular size, two correlated factors [32], were taken into account, the significant gender difference disappeared [30]. The significant correlation of UWSFR with BMI in the present study was in agreement with previous reports $[3,11]$. Since the correlation coefficient between BMI and age was moderately strong in this sample, the result that BMI lost its significant effect on UWSFR was unsurprising result in multivariate analysis. In agreement with earlier reports [6], we found no differences in UWSFR existing between smokers and nonsmokers.

We conclude that UWSFR in this adult Jordanian population ranged between 0.1 to $1.6 \mathrm{ml} / \mathrm{min}$ and patients with as low as $0.10 \mathrm{ml} / \mathrm{min}$ had no signs or symptoms of oral dryness. To evaluate our results about the lowest normal rate of UWSFR, it would be necessary further to study patients diagnosed with xerostomia. Of the demographic factors/ parameters we tested in this study, only age and number of missing teeth contributed consistently to the variability in resting salivary flow rate in this population.

\section{References}

1. Atkinson JC, $\mathrm{Wu}$ AJ. Salivary gland dysfunction: causes, symptoms, treatment. J Am Dent Assoc 1994;125(4):409-416.

2. Ship JA, Pillemer SR, Baum BJ. Xerostomia and the geriatric patient. J Am Geriatr Soc 2002;50(3):535-543.

3. Yamamoto K, Kurihara M, Matsusue Y, Imanishi M, Tsuyuki M, Kirita T. Whole saliva flow rate and body profile in healthy young adults. Arch Oral Biol 2009;54(5):464-469.

4. Sreebny LM, Valdini A. Xerostomia. A neglected symptom. Arch Intern Med 1987;147(7):1333-1337.

5. Marton K, Madlena M, Banoczy J, Varga G, Fejerdy P, Sreebny LM, Nagy G. Unstimulated whole saliva flow rate in relation to sicca symptoms in Hungary. Oral Dis 2008;14(5):472-477.

6. Fenoll-Palomares C, Munoz Montagud JV, Sanchiz V, Herreros B, Hernandez V, Minguez M, Benages A. Unstimulated salivary flow rate, $\mathrm{pH}$ and buffer capacity of saliva in healthy volunteers. Rev Esp Enferm Dig 
2004;96(11):773-783.

7. Navazesh M, Mulligan RA, Kipnis V, Denny PA, Denny PC. Comparison of whole saliva flow rates and mucin concentrations in healthy Caucasian young and aged adults. J Dent Res 1992;71(6):1275-1278.

8. Longman LP, Higham SM, Rai K, Edgar WM, Field EA. Salivary gland hypofunction in elderly patients attending a xerostomia clinic. Gerodontology 1995;12(12):6772.

9. Flink H, Bergdahl M, Tegelberg A, Rosenblad A, Lagerlof F. Prevalence of hyposalivation in relation to general health, body mass index and remaining teeth in different age groups of adults. Community Dent Oral Epidemiol 2008;36(6):523-531

10. Bergdahl M. Salivary flow and oral complaints in adult dental patients. Community Dent Oral Epidemiol 2000;28(1):59-66.

11. Percival RS, Challacombe SJ, Marsh PD. Flow rates of resting whole and stimulated parotid saliva in relation to age and gender. J Dent Res 1994;73(8):1416-1420.

12. Shern RJ, Fox PC, Li SH. Influence of age on the secretory rates of the human minor salivary glands and whole saliva. Arch Oral Biol 1993;38(9):755-761.

13. Marton K, Boros I, Fejerdy P, Madlena M. Evaluation of unstimulated flow rates of whole and palatal saliva in healthy patients wearing complete dentures and in patients with Sjogren's syndrome. J Prosthet Dent 2004;91(6):577-581.

14. Dawes $C$. The unstimulated salivary flow rate after prolonged gum chewing. Arch Oral Biol 2005;50(6):561563.

15. Flink H, Tegelberg A, Lagerlof F. Influence of the time of measurement of unstimulated human whole saliva on the diagnosis of hyposalivation. Arch Oral Biol 2005;50(6):553-559.

16. de Almeida Pdel V, Gregio AM, Machado MA, de Lima AA, Azevedo LR. Saliva composition and functions: a comprehensive review. J Contemp Dent Pract 2008;9(3):72-80.

17. Bjornstad L, Crossner CG. Stimulated salivary flow rate and buffer effect in schoolchildren from Greenland and Sweden: a comparative study. Acta Odontol Scand 2007;65(3):162-166.

18. Bretz WA, do Valle EV, Jacobson JJ, Marchi F, Mendes S, Nor JE, Cancado MF, et al. Unstimulated salivary flow rates of young children. Oral Surg Oral Med Oral Pathol Oral Radiol Endod 2001;91(5):541-545.

19. Crossner CG. Salivary flow rate in children and adolescents. Swed Dent J 1984;8(6):271-276.

20. World Health Organization. Oral health surveys: basic methods. 4th ed. Geneva; 1997.

21. Navazesh M, Kumar SK. Measuring salivary flow: challenges and opportunities. J Am Dent Assoc 2008;139 Suppl(35S-40S.

22. Pedersen W, Schubert M, Izutsu K, Mersai T, Truelove E. Age-dependent decreases in human submandibular gland flow rates as measured under resting and poststimulation conditions. J Dent Res 1985;64(5):822-825.

23. Yeh CK, Johnson DA, Dodds MW, Sakai S, Rugh JD, Hatch JP. Association of salivary flow rates with maximal bite force. J Dent Res 2000;79(8):1560-1565.

24. Scott J. Quantitative age changes in the histological structure of human submandibular salivary glands. Arch Oral Biol 1977;22(3):221-227.

25. Baum BJ. Evaluation of stimulated parotid saliva flow rate in different age groups. J Dent Res 1981;60(7):12921296.

26. Roesink JM, Terhaard CH. The influence of clinical factors on human stimulated parotid flow rate in cancer and other patients. Oral Oncol 2002;38(3):291-295.

27. Heft MW, Baum BJ. Unstimulated and stimulated parotid salivary flow rate in individuals of different ages. J Dent Res 1984;63(10):1182-1185.

28. Osterberg T, Birkhed D, Johansson C, Svanborg A. Longitudinal study of stimulated whole saliva in an elderly population. Scand J Dent Res 1992;100(6):340-345.

29. Leone CW, Oppenheim FG. Physical and chemical aspects of saliva as indicators of risk for dental caries in humans. J Dent Educ 2001;65(10):1054-1062.

30. Inoue H, Ono K, Masuda W, Morimoto Y, Tanaka T, Yokota M, Inenaga K. Gender difference in unstimulated whole saliva flow rate and salivary gland sizes. Arch Oral Biol 2006;51(12):1055-1060.

31. Parvinen T, Larmas M. Age dependency of stimulated salivary flow rate, $\mathrm{pH}$, and lactobacillus and yeast concentrations. J Dent Res 1982;61(9):1052-1055.

32. Ono K, Inoue H, Masuda W, Morimoto Y, Tanaka T, Yokota M, Inenaga K. Relationship of chewing-stimulated whole saliva flow rate and salivary gland size. Arch Oral Biol 2007;52(5):427-431. 